\title{
Medium Communication and Testing of Cooperative or Competitive Tendencies using Prisoner's Dilemma Games
}

\author{
Eko Giyartiningrum Heri Prasetyo \\ Management program, Cokroaminoto University, Perintis Kemerdekaan Street, Yogyakarta, Indonesia
}

\begin{abstract}
This study aims to test whether the media used can predict the individual's tendency to collaborate (cooperatively) or compete in the negotiation process, and whether the use of certain media affects the maximum joint payoff of the negotiation process. This research is expected to contribute theoretically to the development of concepts concerning media richness and electronic negotiations as well as prisoner's dilemma games. This study uses an experimental design to explain the tendencies of collaboration and competition by using Prisoner's Dilemma Games. The participants are students from management programs at two universities in Indonesia. There are some limitations in this article, namely, the research model still has limitations in explaining the behavior of negotiators in making decisions, especially on negotiations with computer media. In fact, the use of computer media in negotiations encounters a number of geographic constraints, ie distance and time differences which may greatly affect the outcome of negotiations under different conditions of the study.
\end{abstract}

Keywords: medium, negotiation, cooperative, competitive, Prisoner's dillema games, payoff, outcome

DOI: $10.7176 /$ EJBM/13-15-03

Publication date:August $31^{\text {st }} 2021$

\section{Introduction}

The basic needs of organizations is the ability to communicate. Members communicate with each other with the Member organizations as well as individuals outside the organization to achieve their goals. There are many available media to support the communication needs such as face-to-face, written document, and the newer forms of communication such as voice mail and video teleconferencing.

Research results indicate that communication media have a significant impact on negotiations. Negotiation is a form of social interaction that seeks to make joint decision issues. The ability of negotiators to effective communications crucial to successful negotiation.

One of the most widely applied theories on media usage is the theory of media wealth. This theory suggests that accomplishing of tasks will increase as the task requirements match the media's ability to convey information (Daft and Lengel, 1986). They conclude that information-rich media such as face-to-face is better suited for a kind of equivocality, whereas less rich media (e.g. email) are suitable for uncertainty. On a vague task where there are multiple interpretations of available information, whereas on the types of uncertain tasks there is a lack of information.

The theory of media richness will get on the assumption that increased media wealth was associated with increased social or physical presence (Zmud et al, 1990). Although the ability of the communication medium is important to support the various communication processes that occur in a face-to-face context, there appears will other dimensions will suppose important to consider. A number of new computer-facilitated innovations (such as email, group support systems, voice mail, video teleconferencing) emerged after developing media richness theory, but this was not a significant problem due to newer electronic media such as audio and Videos have entered and fit with the media richness theory (El-Shinnawy and Markus, 1992).

Purdy (2000) in a study examining the impact of medium on the negotiation outcomes of concluded that the communication medium used for negotiation will choose with carefull. The communication medium determines how much negotiators access to perceptions and communication cues affecting the semantic, syntax and style of the negotiator (Fulk et al, 1990). This study aims to decide the ability of communication media used in predicting the tendency of people to act cooperatively or competitively.

This study aims to test whether the media used can predict the individual's tendency to collaborate (cooperatively) or compete in the negotiation process, and whether the use of certain media affects the maximum joint payoff of the negotiation process.

\section{Literature studies and hypotheses development}

\subsection{Media Richness Theory}

Media Richness Theory (MRT) was first introduced by Daft and Lengel (1986) to answer the question of why organizations are processing, and they proposed a conceptual framework for sorting communication media from richest to leanest. The richness order of the various communication media is fixed and independent of the individual and organizational context in which the communication medium is used.

Media Richness Theory argues that technology collaboration varies from the media's richness side. Media 
richness is ability of the medium to alter understanding within a given time interval. There are 4 factors that influence the richness of a medium that is 1) the ability of the medium to transmit cues, 2) the proximity of feedback, 3) variation of language and 4) personal focus on technology.

Media Richness Theory views media communications based on the media's ability to convey information. An relate with media richness theory, Sitkin, Sutcliffe, and Barrios-Choplin (in Minsky \& Marin, 1999) mention there are two components of media wealth determinants, namely the ability to convey information and the ability to convey information about individual carriers of information. Thus, the focus of the media richness theory is on the ability of medium to provide feedback, non verbal cues, preserving the integrity of messages, and presenting emotional expressions. Based on these criteria, media wealth theory put face to face communication as the richest media, followed by video conferencing, synchronous audio (phone), text-based chat, asynchronous audio / email, and threaded discussion.

Testing of this theory is mostly done to check the suitability of media, not on the actual effects of media use (Rice, 1992). Usually managers are asked to select the media to be used to send a set of hypotheses to determine whether their choices match the predictions of media wealth theory (Daft and Lengel, 1988). The results of these studies are not entirely convincing. In some cases, managers have obtained different results than those predicted by media richness theory (Carnevale, 1981).

Previous studies have compared the impact of different uses of communication media. These studies show that media can affect the nature of communication, but that certain effects depend on the type of task (Reder and Concklin, 1987). For some tasks there is no difference due to media usage, but for other tasks there is a dramatic difference.

Mark (1994) conducted a number of empirical studies related to media wealth theory. But precisely the results of research given contrary to the theory. The conclusion is that the use of some communication media is inconsistent with media wealth theory. This is reinforced by other studies that provide the same conclusion. As a result of this opinion came to reject the idea that richness communication is invariant, and only as a property of the communication media itself.

Some authors have conducted CMC experiments to test a wealth of technical information on behavior. Jansen et.al (1999) found significant differences between the various forms of communication (i.e. text chat, text-to-speech and voice) with voice communication at the highest level of coöperation. Brosig et.al (2002) found evidence that cooperative levels were much higher in video and table conferences compared with other treatments (other collaboration media) such as audio conferences, lectures and talk shows.

\subsection{Computer-mediated communication}

There is a very rapid increase in the number of organizations and people who use media for communication such as computer mediated communication (CMC) (Hunt, 1999). The use of new technologies such as computer chat and video conferencing increases. Negotiators must choose or use various technologies without knowing the impact of those choices.

Initial research on the role of $\mathrm{CMC}$ shows that non-face-to-face communication is inherent and will inhibit develop interpersonal relationships, including the form of relationships between business partners after the negotiation. The research argument is that $\mathrm{CMC}$ eliminates vocal cues and facial expressions of negotiators that are important in building a relationship. CMC does not accommodate the social relations processes that occur during face-to-face negotiations (Culnan and Mark, 1987). Similar results are found in the negotiation literature that negotiators who do not see partners are more contemporary (contradictory) and less cooperative. Thus miscommunication will occur more often in email usage than telephone communications.

Rice and Love (1987) argue that CMCs can not be compared with face-to-face interactions. The argument is that CMCs are not suitable for negotiation or to persuade others, because of the limited CMC capabilities of the audio and visual cues present in the interaction. Therefore, they argue that CMC interactions contain only a small amount of socioemotional content.

Although the study of communication competence is still being debated (McCroskey, 1982, Rubin et al, 1993, Wieman, 1977), everyone agrees that communication competence is a very important part of a healthy communication relationship (Wrench et al., 2007). DeSannctis and Monge (1999) suggest that CMC is more effective than face-to-face communication for divergent tasks. Divergent tasks are tasks that need creative ideas by exploiting many possible solutions. Whereas face-to-face communication is more compelling for concurrent errands such as decision-making that require interdependency on others. Archee (1993) found evidence that faceto-face groups were better at making decisions from the CMC group because face-to-face groups were more likely to reach agreement at the same time using either verbal or non-verbal responses at a time, while the CMC group was slower in Giving non-verbal feedback as well as uncertainty in expressing their reactions. Strans and Grath (1994) also argue that face-to-face communication is superior to CMC especially for tasks that need high interdependence. Biccheri et al. (2007) found evidence that the impact of communication varied by wealth or communication channel. Videoconference produces a very close level of coöperation with Face-to-face 
communication, while text-based communication results in less substantive coöperation. Generally the impact of $\mathrm{CMC}$ approaches the impact of face-to-face communication because CMC is a communication channel that produces face-to-face communication features.

\subsection{Negotiation theory}

An important paradigm that underlies behavioral analysis in negotiations is that individuals behave according to their motivations. Thus developed a motivational orientation that guides and strategies that guide individual behavior in resolving conflict (Kilman and Thomas, 1977). The study of motivation orientation was initiated by Deutsch (1949) which states that managers should analyze the forces of conflict based on two axes: focus on self-interest or focus on the interests of others. Dual concern model shows 5 conflict styles that depend on the level of concern that is competing, reflecting individuals who focus on resource distribution dominance; Collaborating, describes individuals who seek to maximize mutual benefits and seek new value opportunities; accommodating, relating to individuals who focus on the separation of differences; And avoiding, describes individuals who withdraw from the conflict and hope not to deal with others. These approaches have been tested in various fields of research from clinical psychology to information systems project management.

From the economic context, game theory ensures that people will behave along the two poles of an eczema competitive called "zero sum game" to a cooperative (e.g. collaboration) called "non zero sum game.' Concerning the bargaining situation, in a study, more than 1600 global executives, Shell (2001) found that competition and collaboration orientation was found in many trading environments where people were actively involved in the bargaining process.

From a behavioral perspective, individuals behave depending on the structure of their preferences which is an aggregate of the advantages of self and others. Individuals are called collaborative if they support increasing self-worth and value for others, and the individual is called competitive when the individual seeks to expand its ownership and hinders others from extending their ownership.

Negotiation is a process caused by parties with conflicting preferences exchanging information in the hope of reaching an agreement. This requires the parties to work together to build solutions and compete to secure the distribution of resources (Chen, 2010 Concession (concession) could be a development made by one arbitrator as a greatness of the distinction between the proposed final-offer (Vetchera, 2007). The movement is evaluated based on the last offer, and can be classified according to:

a. Integrative concession or win-win, allowing both parties to increase their value based on the last offer. The idea of integrative movement is based on activities that allow for profit through value creation.

b. Distributive concession or win-lose, is associated with an increase in value for one side but a decline for the other. Distributive concessions are the norm or rule expected by negotiators, whose benefits to one party are harm to the other.

Distributive bargaining usually consists of 5 stages: 1) each side prepares the negotiation by determining the target and its resistance and the target and resistance of the opponent. The target point is the best realistically achievable result, while the resistance point is the lowest point of the agreement is not reached and will use the best alternative that can be done to negotiate for example filing a court, 2) in the second stage, each party defines the issues and Usually make the first offer or send a proposal, 3) The negotiating parties exchange information about their position and the arguments in favor of the position, 4) They bargain for compromise by reviewing and making a deal, 5) each party executing the agreement negotiation.

\subsection{Game theory}

Game theory is a part of science related to decision-making when two or more parties are in a state of competition or conflict. The competing parties are assumed to be rational and intelligent. This means that each party will adopt a rational strategy of action to win the competition and each party also knows the strategy of the other party. Game theory can explain a well-known paradox, namely how people can work together in society when them tends to try to be a winner.Game model is a fundamental static model (fundamentally static model) that is more focused on the outcomes than the process. This model assumes that the number and identity of the player is fixed and known, the player is very rational, the alternatives and functions of the utility are fixed and unknown, the communication only exists in the model and does not affect either the form or content of payoff matrix (Huatlim, L \& I Banbasat, 1992).

In this theory, two conflicting decision makers know or at least have information about their behavior and know the value of the game. In addition, as a game or a competition, a player will always position himself as the party to win the game. Therefore, player I is positioned as a player who will maximize his victory, and player II is positioned as a player who will minimize defeat. Rationally, each player will react to choose the most profitable strategy. If one chooses a lucrative alternative strategy, then so does his opponent. In this case, the decision makers know the strategy to be taken by the opponent, as well as the possible value of the decision or payoff for each strategy. 
Game theory can be classified by 1) number of players, (2) Game value, and (3) Game Strategy. Based on the number of players, at least two people or two groups, so this theory distinguishes the type of game into two person games and $\mathrm{n}$ person games. In practice, game competition can be performed by a company when it comes to issuing new products, product pricing, or other policy determinations that will make competitors or other companies react. From the player's point of view, in this theory, the player's value may be the same or may be different for each chosen strategy. If the player's game value that maximizes victory equals the player's value that minimizes defeat, then the game is known as the zero sum game value. Conversely, if the game value between two players is different, then the game is known as a non-zero sum game value. From the strategy side of the game, selected by the player. If the game value contains a saddle point or horse saddle that causes the maximum game value, the player who will win the game equals the minimum value of the player who will minimize the game. Therefore, the strategy to be chosen is pure strategy games (pure strategy games). Conversely, if the value of the game does not contain a horse saddle point that causes the two players may not have the same value, then the strategy game that will be selected is a mixed strategy game (mixed strategy games).

\section{a. Prisoner's Dilemma}

In the game of two people, it can happen the value of a player's victory is different from the value of the opponent's defeat. The situation where the winning player score is not equal to the player's losing score in the game matrix, the total game value is not equal to zero so this type of game is called a two-person game with a non-zero sum game.

John von Neumann and Oskar Morgenstern (1944), and A.W. Tucker (1950) introduces the term prisoner's dilemma as part of game theory and is more generally part of the rational choice theory. This dilemma is not a zero sum game that leads to balance. On the contrary, it often produces things far from expectations.

The prisoner's dilemma is shaped like a story. There are two suspected crimes interrogated separately. If one of them confessed to doing evil while the other did not confess, who claimed to be released while the nonadmitted were punished severely. If they both confess, then they are both punished. On the contrary, when both are in unison, both are punished lightly. In the case of the classic prisoners' detention dilemma, it was described that the police arrested two suspects of a criminal case. They were interrogated separately, and there was no communication between them. Since the evidence is not enough, the police give them two options to deny or acknowledge their involvement. If both deny, then $\mathrm{A}$ and $\mathrm{B}$ will be sentenced to 1 year imprisonment. If $\mathrm{A}$ denies and B confesses, then A will be rewarded 10 years in prison, and B is free. If A confesses and B denies, then $\mathrm{A}$ is free and $\mathrm{B}$ gets a 10-year sentence. If both confess, each will be rewarded 10 years. Payoff of this case can be seen in the following table:

Table 1. The payoff matrix of prisoner's dilemma games

\begin{tabular}{|l|l|c|c|}
\hline \multicolumn{2}{|c|}{ Strategy } & \multicolumn{2}{c|}{ Prisoners B } \\
\cline { 3 - 4 } \multicolumn{2}{|l|}{} & Defection & Cooperation \\
\hline Prisoners A & Defection & $-1,-1$ & $-10,0$ \\
\hline & Cooperation & $0,-10$ & $-8 .-8$ \\
\hline
\end{tabular}

For player A, if B denies, A will choose to confess $(0>-1)$, and if B confesses, A will still choose to confess $(-8>-10)$. Thus, for A "confess" is the dominant strategy, because whatever strategy B chooses, the "confessing" payoff for $\mathrm{A}$ is always higher than other A strategy payoffs. For B, if A denies, B will choose to confess $(0>-1)$, and if A confesses, B will still choose to confess $(-8>-10)$. Thus, for B "to confess" is the dominant strategy, because whatever strategy A chooses, payoff "confess" to B is always higher than other B strategy payoffs. Therefore, the outcome claimed to be the best opinion for both suspects.

Several studies have tried to see how the influence of communication media on interaction between individuals. Many studies have compared different aspects of social interaction and communication in the media. Media wealth affects perceptions in virtual work teams. Cognitive and certain media styles contribute to the commitment of the virtual work team and telework. Some hypothesis proposed in this research is 1) Negotiators who use video presentation will tend to use a cooperative approach rather than a negotiator using a web blog (leaner media), 2) Negotiators who use web blogs tend to use a competitive approach rather than a negotiator who uses video presentations, 3) Co-operative negotiators tend to use integrative concessions rather than distributive concessions, 4) Competitive negotiators tend to use distributive concessions rather than integrative concessions, 5) The distributive concession will provide the lower joint gains, 6) An integrative concession will provide maximum joint gains

\section{Research methods}

\subsection{Method, procedures and participants}

This study uses an experimental design to explain the tendencies of collaboration and competition by using Prisoner's Dilemma Games. The participants are students from management programs at two universities in Indonesia. 
The dependent variable in this experiment is the outcomes represented in the form of the maximum payoff agreed by both negotiating parties. The dependent variable is a variable that is explained or influenced by an independent variable. Measurement of this variable is done by giving manipulation on the independent variable. To find out if the participant tends to use a cooperative or competitive negotiation approach tested by solving cases in the game's prisoner's dilemma and to find out if the participant tends to take an integrative or distributive negotiation concession then the participant is asked to negotiate the case in the prisoner's dilemma game.

The experimental design used in this research is between-within-subject with $2 \times 2 \times 2$ factorial design, because there are two approaches to negotiation (cooperative and competitive), 2 negotiation concessions (integrative and distributive) and there are 2 media used (video presentation And web blogs), so there will be 8 experimental groups.

This research was conducted with 2 experimental stages. In the first stage of the experiment, the participants were randomly divided into 3 large groups: participants who used web blogs and participant groups using video presentation media and control groups, the group that did the first experiment without using video presentation media and web blog media. The three groups of participants will complete six kinds of prisoner's prisoner game.

In the second stage, each group will get the next treatment. Participants are divided into small groups of between two people each, and each pair of the group will settle the case of negotiation. Negotiations between couples for the experimental group (video presentations and web blogs) were conducted through electronic mail communication media and for the control group were conducted by a direct face-to-face method. This is to determine whether participants from cooperative and competitive groups will tend to take distributive negotiation concessions or integrative concessions.

Prior to the experiment, the instrument of research is first tested through pilot experiment, to initial investigation conducted with the main objective to test the readiness of the experimental instrument so as to reduce the weaknesses that may arise due to the instruction and tasks on the research instrument (Gould, 2001). The pilot test results are then used as inputs in developing the final research instrument to be tested in the real experiment.

Participants are S1 students who have filled out the willingness sheet to follow the experiment. The participants of this study were randomly divided into 3 groups: experimental groups (using video presentation media and groups using web blogs), and control groups. After the randomization process, participants are asked to do the whole game (games) provided. Randomization is intended to improve internal validity. In addition to randomization problems, Cooper and Chindler (2006) stated that in order to improve internal validity capability, experimental design should be considered in the form of history, maturity, instrumentation, experimental mortality, and selection.

Participants receive referral guidance in the form of general instructions given. In the experimental process, participants are asked not to discuss each other's decision with other participants except in the case of negotiation and only allowed with each negotiating partner. Any information provided by the participants kept confidentially.

The first experiment used four types of manipulation: 1) six cases of prisoners 'prisoner games displayed via web blog, 2) six cases of prisoners' prison games displayed via video presentation, 3) one case of negotiation displayed via web blog, and 4) one case of negotiation displayed via presentation Videos.

Each participant will complete 2 experimental stages. The first experiment contained a case of a prisoner's dilemma game and a second experiment containing one case of negotiation. The estimated time for the case in the first experiment was 3 to 4 minutes, so the total time required for the first experiment for each treatment group was 18 to 20 minutes. In the second experiment, the estimated time is 15 minutes, so the total time required to complete the experiment is 35 minutes. This condition is intended to avoid the effects of boredom and fatigue when participants too long to follow the experiment.

The completed experimental stage generates a number of observational data in the form of experimental forms. The forms are subsequently collected and recaptured in the MS Excel application according to the type of treatment being experimented. Recapitulation results are then used as a basis for conducting statistical testing and discussion.

\section{Analysis and result}

The experimental results of 22 participants (44 percent) using presentation videos tend to take a cooperative negotiation approach and 5 participants (10 percent) tend to take a competitive approach. For participants using web blogs, as many as 19 people (39 percent) tend to take a cooperative approach and 4 participants ( 8 percent) tend to take a competitive approach. Of the 50 participants, 41 ( 82 percent) tend to be cooperative and the remaining 9 participants (18 percent) tend to be competitive. Thus, it can be argued that participants of the experimental group tend to be cooperative rather than competitive.

In the experimental results of 27 participants using presentation videos, 19 participants (38 percent) took an integrative cooperative approach, 4 participants $(8$ percent) took a cooperative approach, 2 participants (4 
percent) took an integrative competitive approach and 3 participants ( 6 percent). Take a distributive competitive approach. For participants using a web blog, 13 participants (26 percent) took an integrative cooperative approach, 6 participants (12 percent) took a distributive cooperative approach, 1 participant took an integrative competitive approach and 3 participants ( 6 percent) took a distributive competitive approach.

The results of the control group experiment were 14 participants (64 percent) tended to take a cooperative negotiation approach and only 8 participants (36 percent) tended to take a competitive approach. Of the 22 participants in the control group, 13 participants (59 percent) took an integrative cooperative approach, 1 participant ( 5 percent) tended to take a distributive cooperative approach, 2 participants ( 9 percent) tended to take an integrative competitive approach and 6 participants $(27$ percent) Competitive distributive.

To find out whether there is a correlation between the medium used and the tendency of participants to take a cooperative or competition attitude, a chi-square test is performed. Test results maintain that Asymp. Sig. (2sided) is 0.918. The value is greater than 0.05. Thus it can be concluded that Ho accepted or no relationship media use with the approach of negotiation. This means that media has nothing to do with participants' tendency to make cooperative decisions or the tendency of participants to make competitive decisions. Thus hypothesis 1 and hypothesis 2 in this study were rejected.

This finding is in contrast to findings from Gettinger et al (2012) which show that information presentation influences the negotiation process. The results show that negotiators who gain access to information in the form of graphs have more integrative behavior in the negotiation than the negotiators who have access to the same information but presented in tabular form.

Referring to the explanation of media wealth theory, the wealth of communication media is based on the media's ability to convey information. Previous studies that have compared the impact of the use of communication media have found results that media can influence the nature of communication, but certain effects depend on the type of task. For some types of tasks, there is no difference due to media usage, but for other tasks, there is a dramatic difference.

Testing of hypothesis 3 san 4 is Asymp. Sig. (2-sided) is 0.014 . The value is less than 0.05 . Thus it can be concluded that Ho is rejected or there is a relationship approach negotiation with the negotiation concession. This means that negotiation concessions are influenced by cooperative or competitive negotiation approaches taken by participants. Thus hypothesis 3 and hypothesis 4 in this study are accepted.

Negotiation is a cognitive decision-making process that involves consideration of the object in question and demands the determination of acceptable behavior by interested parties. Negotiation requires a good cognitive structure that is based on the experience of the negotiator (Pinkley, 1990).

Individuals behave depending on their preference structure which is an aggregate of self-gain and others. Individuals are called collaborative if they support increasing self-worth and value for others. Individuals are called competitive when individuals seek to expand their holdings and discourage others from expanding their holdings. Parties working together to build solutions and compete for securing the distribution of resources will take action called concessions. Such concessions may be integrative concessions based on activities that enable profitability through value creation and distributive concessions where benefits to one party are harm to the other. Thus, this argument can support the evidence from the statistical tests for hypothesis 3 and hypothesis 4 in this study that the negotiation approach relates to a negotiation concession. Cooperative negotiators tend to use integrative concessions, and competitive negotiators tend to use distributive concessions.

For testing hypotheses 5 and 6 it is seen that Asymp. Sig. (2-sided) is 0.040. The value is less than 0.05. Thus it can be concluded that Ho is rejected or there is a concession negotiation relationship with joint gains (outcomes). This means that the negotiating concessions affect the joint gains (outcomes) obtained from the negotiation process. Thus hypothesis 5 and hypothesis 6 in this study are accepted.

Win-lose orientation is contrary to win-win orientation, defined as the belief that negotiation is the process of finding the maximum solution for the sake of one party. A number of studies have found out that win-lose orientation influences bargaining behavior and has an effect on achieving optimal outcomes (Larrick and Blount, 1997).

Some research on social dilemmas lend support that individualists can work together if they get a cooperative signal from their negotiating opponents. These studies found evidence that individualists responded to cooperative signals and took a strategy toward tit-for-tat. Schei, et.al, (2011) contends that by expanding these reasons toward blended dyads in arrangements, cooperators can give integrator agreeable signals) that energize individualists to coöperate (integrator behavior) instead of competition (distributive behavior). Thus, this argument can support statistical test evidence for hypothesis 5 and hypothesis 6 in this study.

The result of testing to the control group is the value of Asymp. Sig. (2-tailed) of 0.057 . This value is greater than the value of $p$ value $0.05(0.057>0.05)$, it can be concluded that Ho is accepted, meaning that there is no difference in negotiation approach (cooperative and competitive tendencies) in the experimental class participants and control class participants. Whether participants are informed of a prisoner's dilemma game dilemma from video presentation media, web blog media or reading on paper (without electronic communication 
media) does not affect their decision to act cooperatively or competitively. This means that participants' tendencies for cooperative and competitive are not influenced by the medium of communication. The results of hypothesis testing 1 to 6 can be summarized in the table below:

Table 2. Summary of hypothesis testing results

\begin{tabular}{lll}
\hline Hypothesis & \multicolumn{1}{c}{ Accepted } \\
\hline Hypothesis 1 & $\begin{array}{l}\text { Negotiators who use video presentation } \\
\text { approach rather than a negotiator using a web blog (leaner media). }\end{array}$ \\
Hypothesis 2 & $\begin{array}{l}\text { Negotiators who use web blogs tend to use a competitive approach rather than a } \\
\text { negotiator who uses video presentations. } \\
\text { Co-operative negotiators tend to use integrative concessions rather than } \\
\text { distributive concessions, }\end{array}$ & $\sqrt{ }$ \\
Hypothesis 3 & $\begin{array}{l}\text { Competitive negotiators tend to use a distributive concession rather than an } \\
\text { integrative concession. } \\
\text { The distributive concession will provide the lower joint gains. }\end{array}$ & $\sqrt{ }$ \\
Hypothesis 5 & H6: An integrative concession will provide maximum joint gains & $\sqrt{ }$ \\
\hline
\end{tabular}

\section{Discussion and conclusion}

Compared to face-to-face communication, the main weakness of computer-mediated communications (CMC) is the lack of visual and audio cues (Vrasidas and Mclsaac, 2000). Body language or movement often conveys importance. Studies on computer based communication mostly use text-based CMC. The difference with this research is that the development of information technology led to communication with information technology (ITC) also experienced rapid development. These developments cause the web blog is no longer just a collection of posts or links that are stored by the owner of the blog, but already provides other services such as services to upload photos or video. Thus there is virtually no difference between communication media with CMC and faceto-face communication. In this study participants can read cases of prisoner game prisoners then understand as well as the understanding of participants who use video presentations and control group participants who read the text of cases of prisoners' dilemma on paper.

Bichieri et al (2007) found evidence that the impact of communication varied according to the richness of the communication channel. Videoconference produces very close cooperation with face-to-face communication, while text-based communication results in less substantive cooperation. Generally, the impact of CMC approaches the impact of face to face communication because $\mathrm{CMC}$ is a communication channel that reproduces the face to face communication features.

The statistical evidence for hypothesis 5 and hypothesis 6 obtained in this study is not in line with the Buchieri et al (2007) study. In the 2nd experiment for the control class and the experimental class, there was no difference in the outcome of the negotiation. The two groups gave the same result that the negotiation concessions had an effect on the joint payoff. For the control group, negotiations were conducted with face-toface media, while for the experimental group negotiations were conducted with electronic mail. Thus it can be concluded that text-based communication or negotiation (email) and face to face negotiation do not affect the outcome of a negotiation.

This study finds evidence that there is no relationship between media use and the negotiated approach. The use of electronic collaboration media of video presentations and web blogs is not related to the tendency of participants to make cooperative or competitive decisions. Thus there is not enough evidence to accept hypothesis 1 that negotiators using presentation video (richer media) will tend to use a cooperative approach. Similarly, with hypothesis 2 , there is not enough evidence to accept the hypothesis that negotiators using web blogs (leaner media) will tend to use a competitive approach.

There is ample evidence to accept the hypothesis that the negotiation approach affects negotiation concessions. Cooperative negotiators will tend to use integrative concessions rather than distributive concessions, and competitive negotiators will tend to use distributive concessions rather than integrative concessions.

There is sufficient evidence to accept the hypothesis that negotiation concessions affect the joint payoff. The integrative concession will provide the maximum joint gains and the distributive concessions will provide lower joint gains. This is because distributive concessions lead to benefits on the one hand and cause losses on the other, so negotiators with distributive concessions tend to take maximum advantage for their side and cause lower joint gains.

\section{Implication, limitation and future research direction}

This study contains at least three implications of research, namely conceptual implications, methodologies and managerial. Conceptually, this research has successfully approached the Media richness Theory by using the Prisoner's Dilemma Game. Thus, the empirical results of this study will further enrich the exploration of Media Richness Theory which has been using perspective and approaches different from that done in this research. 
This research can at least be used as one of the foundations in developing behavioral research in the field of Management Information System including the research methodology used. Although the research methodology developed in this study is still not perfect, at least able to provide new colors in the field of behavioral research in the field of Management Information Systems.

In addition to the above two implications, this study also contains managerial implications. From the managerial side, the results of this research are at least able to provide policy contribution for practitioners who very often do business negotiations in the area of information systems and other business areas.

This study contains several limitations. The research model still has limitations in explaining the behavior of negotiators in making decisions, especially on negotiations with computer media. In fact, the use of computer media in negotiations encounters a number of geographic constraints, ie distance and time differences which may greatly affect the outcome of negotiations under different conditions of the study.

Another limitation is the use of cases of prisoners' dilemma of only 6 cases. The use of these may be true to the trend of negotiator behavior. More cases need to be added so that conclusions can be taken to see the tendency of negotiators to be cooperative and competitive can be more meaningful.

Suggestions for future research that can be submitted authors are; a) For academics and researchers. The empirical findings in this study have shown that the complexity of negotiator behavior can not be explained simply by using only one perspective or approach. So for future research, researchers need to combine with some other perspectives and with other methodologies to obtain better research results in explaining the behavior of negotiators in making decisions, especially for negotiated cases mediated by electronic or computer media, b) For practitioners, an understanding of the psychological aspects of the negotiation process is essential to improve the quality of the decisions taken. Understanding of conditions as in the game of the prisoner's dilemma is also very good to understand the decisions taken can provide maximum benefits for the negotiating parties.

\section{References}

Archee, R. Using computer-mediated communication in an educational context: Educational outcomes and pedagogical lessons of computer conferencing. The electronic Journal of communication, 3 (2), 1993.

Bichieri, C et.al. Computer-mediated communication and cooperation in social dilemmas: an experimental analysis. Politics, Philosophy \& Economic Journal p. 139. SAGE Publication Ltd. 2007.

Bordia, P. Face-to-face versus computer-mediated communication: A synthesis of the experimental literature. The Journal of Business Communication, 34 (1), 99-120. 1992.

Brosig, Jeannette, 2002. Identifying cooperative behavior: some experimental result in a prisoner's dilemma game. Journal of Economic Behavior \& Organization Vol. 47, 275 - 290.

Bhaskaran S. R., V. Krishnan. E⿺ort, revenue, and cost sharing mechanisms for collaborative new product development. Management Science. 55(7), 1152-1169. 2009.

Carnevale, P., Pruitt, D., \& Seilheimer, S. 1981. Looking and competing: Accountability and visual acccessn in integrative bargaining. Journal of Personality and Social Psychology 40. 111-120

Chai, G., Kock, N. An evolutionary game theoretic perspective on e-collaboration: The collaboration effort and media relativeness. European Journal of Operational Research 194, 821 - 833. 2009.

Chen, Eva. Collaboration and competitive e-negotiation: analysis of communication on concessions. InterNeg Research Paper, John Melion School of Business, 2010.

Croson, R. T., Look at me when you say that: on electronic negotiation simulation. Simulation and Gaming 31 (1): 23-37, 1999.

Daft, R., Lengel, R. Organizational information requirements, media richness and structural design. Management Science 32 (5), 554 - 571, 1986.

Daft, R., Lengel, R., Trevino, L., Message equivocality, media selection and manager performance: Implication for information system. MIS Quarterly 11 (3), 355 - 366, 1987.

Dennis, A.R., Valacich, J.S., Connolly, T., \& Wynne, B.E, Process structuring in electronic brainstorming. Information Systems Research, 7(2), 268-277, 1996.

Dennis, A.R., George, J.F., Jessup, L.M., Nunamaker, J.F. \& Vogel, D.R., Information Technology to Support Electronic Meetings, MISQ, 12, 4, 591-624. 1988.

Dennis, A. R., dan J. S. Valacich. Rethinking media richness: Toward a theory of media synchronicity, working paper, 1997.

Dennis, A. R.,\& Kinney, S. T. Testing media richness theory in the newmedia: The effect of cues, feedback and task equivocality. Information Systems Research, 9, 30-33, May. 1998.

Dennis, A. R.,Wixom, B., \& Vandenburg, R., Understanding fit and appropriation effect in group support system via meta analysis. MIS Quarterly 25 (2), 167-193, 2001.

DeSanctis, G., \& Gallupe, R., A foundation for the study of group decision support systems. Management Science, 33(5), 589-609, 1987.

DeSanctis, G., \& P. Monge. Introduction to the Special Issue: Communication Processes for Virtual 
Organizations. Organization Science 10.6 (November/December): 693-703, 1999.

Deutsch, M, A Theory of Cooperation and Competition. Human Relations 2: 129-152. 1949.

Eden \& Ackerman, Constrating single user and networked group decision support system for strategy marketing. Group Decision Negotiating 10: 47-66, 2001.

Ellen Bolman Pullins, Curtis P. Haugtvedt, Peter R. Dickson, Leslie M. Fine, Roy J. Lewicki., Individual differences in intrinsic motivation and the use of cooperative negotiation tactics. Journal of Business \& Industrial Marketing, Vol. 15 Iss: 7 pp. 466 - 478, 2000.

Fjermestad, J., \& Hiltz, S., R., An assessment of group support systems experimental research: methodology and results. Journal of Management Information Systems. Volume 15 Issue 3, 7 - 149, 1998.

Foroughi, A., Perkins, W. C., \& Jessup, L. M., A comparison of audio conferencing and computer conferencing in a dispersed negotiation setting: efficiency matters, Journal of Organizational and End User Computing 17 (3): 1-26, 2001.

Fulk, J., Schmitz, J., \& Steinfield, C, A Social influence model of technology use. In J. Fulk and C Steinfield (Eds), Organization and communicationtechnology, pp. 117-140. Newyork Park, CA: Sage, 1990.

Gettinger, Johannes et.al. Shall we dance?-The effect of information presentation on negotiation process and outcomes. Decision Support System 53 pp 161-174, 2012.

Hiltz, S.R., \& Turoff, M. Computer networking among executives: a case study. Journal of Organizational Computing, 1, 4, 357-376, 1991.

Hiltz, S.R., Turoff, M. \& Johnson, K. Experiments in Group Decision Making, 3: Disinhibition, Deindividuation, and Group Process in Pen Name and Real Name Conferences, Decision Support Systems, 5, 2, 217-232, 1989.

Hunt, J. A cheap way to meet: Videoconferencing . Seattle Post-Intelligencer, p. B1. 1999.

Jansen, W., Steenbakkers, W. \& Jagers, H. Electronic commerce and virtual organisations. Special Issue of eJov 1, 1, 54-68. 1999. http://www.virtual-organization.net

Kahai, S., Cooper, R. Exploring the core concepts of media richness theory: The impact cue multiplicity and feedback immediacy on decision quality. Journal of Management Information System 20 (1), 263 - 281. 2003.

Kilmann, R. H., \& Thomas, K. W. Developing a Forced-Choice Measure of Conflict-Handling Behavior: The MODE Instrument. Educational and Psychological Measurement, Vol. 37, No. 2, 309-325, 1977.

King, R.C., Hartman, A., \& Hartzel, K. Message Creation Versatility, Media Capacity, and Media Choice: A Forward Looking Perspective. Proceedings of ICIS, Dallas, TX, 257. 1992.

Kock, N., Asynchronous and distributed process improvement: The role of collaborative technologies. Information System Journal 11 (2), 87 - 110, 2001.

Kock, N., The psychobiological model: Toward a new theory of computer-mediated communication based on Darwinian evolution. Organization Science 15 (3), 327 - 348. 2004.

Kock, N. What is collaboration? International Journal of e-collaboration 1 (1), i-vii. 2005.

Latipun, Psikologi Eksperimen, edisi kedua, Malang: UMM Press, 2008.

Lee, A., Electronic mail as a medium for rich communication: An empirical investigation using hermeneutic interpretation. MIS Quarterly 18 (2), 143 - 157. 1994.

Lengel, R.H \& Daft, R. L., The Selection of communication mdia as ana executive skill. Academiy of management Executive 2 (3), 225-232, 1988.

Lewin, K. Principles of Topological Psycology, McGraw-Hill, New York, NY,1936.

Lim, Lai-Huat, and Izak Benbasat, A Theoretical Perspective of Negotiation Support Systems, Journal of Management Information Systems, Winter 1992-939(3), 27-44, 1992.

Ma, Zhenzhong. Personality and negotiation revisited: toward a cognitive model of dyadic negotiation. Management Research News Vol 31 No. 10 pp 774-790, Emerald Group Publishing Ltd, 2008.

Markus, M., Asynhronous technologies in small face-to-face groups. Information technology and people 6 (1), $29-48,1992$.

Markus, M., Electronic mail as the medium of managerial choice. Organization Science 5 (4), 502 - 527, 1994.

Markus, M., Technology-shaping effect of e-collaboration technologies: Bugs and features. International Journal of e-collaboration 1 (1), $1-23,2005$.

Mennecke, Valacich, \& Wheeler, The effect of media and task on user performance: A test of the task-media fit hyphotesis. Group and Decision Negotiation 9: 507-529, 2000.

Minsky, B. D., \& Marin, D. B. Why faculty members use e-mail: The role of individual differences in channel choice. The Journal of Business Communication, 36 (2), 194-217, 1999.

Nunamaker, J., Dennis, A., Valacich, J., Vogel, D., \& George, J. Electronic meeting systems to support group work: theory and practice at Arizona. Communications of the ACM, 34(7), 40-61, 1991.

Neumann, John \& Morgenstern, Oscar. Theory of games and economic behavior. Princeton University Press, pp. $18-625.1944$. 
Pinkley, R. L. Dimension of conflict frame: disputant interpretation of conflict. Journal of Applied Psychology, Vol. 75, pp 117-26, 1990.

Purdy, J. M., Nye, P. \& Balakrisnan. P. V., The impact of communication media on negotiation outcomes. International Journal of Conflict Management 11 (2): 162-187, 2000.

Putman, L. L., dan Jones, T. S. Reciprocity in negotiation: An analysis of bergaining interaction. Communication Monographs 49, 171-191. 1982.

Rice, R. E. Task analyzability, use of new media, and effectiveness: A multi-site exploration of media richness. Organization Science, 3, 475-500, 1992.

Rice, R.E., Grant, A., Schmitz, J., \& Torobin, J. Individual and network influences on the adoption and perceived outcomes of electronic messaging. Social Networks, 12:1, 27-55, 1990.

Rice, R.E., \& Shook, D. Relationships of job categories and organizational levels to use of communication channels, including electronic mail: A meta-analysis and extension, Journal of Management Studies, 27:2, 1990, 195-229.

Rice, R., \& Love, G., Electronic emotion: socioemotional content in computer-mediated network. Communication Research 14, 85-108, 1987.

Rogers, E. M.Communications technology: The new media in society. New York: The Free Press. 1986.

Sheffield, J. The effect of communication medium on negotiation performance. Group Decision and Negotiation 4 (2): 159-179, 1995.

Shell, G. R Bargaining styles and negotiation: The Thomas-Kilmann Conflict Mode Instrument in negotiation training. Negotiation Journal (April): 155-293, 2001.

Short, J., Williams, E., and Christie, B. (1976). The Social psychology of telecommunications. London: Wiley.

Solso, Robert L, Otto H. Maclin dan M. Kimberley Maclin. Psikologi Kognitif, Edisi ke delapan. Jakarta, Erlangga, 2002.

Suh, K. S., Impact of communication medium on task performance and satisfaction: An examination of media richness theory. Information and Management 35: 295-312, 1999.

Straus, S. G. and McGrath, J. E. Does the medium matter? The interaction of task type and technology on group performance and member reactions. Journal of Applied Psychology, 87-97, 1994.

Thompson, L. Negotiation behavior and outcomes: empirical evidanc and theoretical issue. Psychological Bulletin, Vol. 108, pp. 32-525, 1990.

Vetchera, R. Preference Structures and Negotiators behavior in Electronic Negotiaitons. Decision Support Systems 44(1): 135-146, 2007.

Vrasidas, C., \& McIsaac, M. S. Principles of pedagogy and evaluation for web-based learning. Educational Media International, 37 (2), 105-111, 2000.

Wrench, J.S dan Carter, M. P., Narissra, The relationship between computer-mediated communication, competence, apprehension, self-efficacy, perceived confidence, and social presence. Southern Communication Journal vol. 72, No. 4, pp 355-378, 2007.

Yuan, Y., J. B. Rose and e. al. A Web-Based Negotiation Support system. International Journal of Electronic Markets 8(3): 13-17, 1998.

Zmud, R. W., Lind, M. R., \& Young, F. W. An Attribute Space for Organizational Communication Channels. Information Systems Research, 1 (4), 440 - 457, 1990 